\title{
Tako-tsubo cardiomyopathy in a male patient after administration of isoproterenol and implantation of a pacemaker
}

\author{
Fathia Mghaieth Zghal, Ramy Trabelsi, Sihem Mbarki, Ghassen Cherif, Nidhal Ben Moussa, \\ Mohamed Sami Mourali, Rachid Mechmeche
}

Rabta University Hospital, Faculty of Medicine, University of Tunis El Manar, Tunis, Tunisia

Email: fathiazghal@yahoo.com

Received 28 October 2011; revised 3 December 2011; accepted 17 December 2011

\begin{abstract}
Background: Tako-tsubo cardiomyopathy occurs typically after an intrinsic adrenergic hyperstimulation triggered by a psychological or physically stressful event. Exceptionally, it may be caused by an exogenous hyperadrenergism. We report the case of an 85 year old man, hypertensive, with a history of ischemic stroke. He consulted for signs of heart failure with recurrent dizziness two weeks which was explained by an atrioventricular block. Initial echocardiogramphy showed left ventricular ejection fraction to $60 \%$ with no wall motion abnormalities. The patient received isoprenaline $(0.02 \mathrm{mcg} / \mathrm{kg} / \mathrm{mn})$ for 20 hours before the implantation of a single chamber pacemaker. At 24 hours of admission an acute pulmonary edema occurred. The control echocardiography showed impaired left ventricular ejection fraction of $25 \%$ with apical ballooning and akinesis was also found on ventriculography. Coronary angiography showed no significant coronary lesions. Troponin level was elevated to $2 \mathrm{ng} / \mathrm{ml}$. The pulmonary edema was then controlled. Subsequent clinical and echocardiographic were favorable after two weeks which was consistent with the diagnosis of tako-tsubo cardiomyopathy. Conclusion: This case illustrates an example of tako-tsubo syndrome induced by an exogenous catecholergic stimulation (isoprenaline) combined with an endogenous release after a pacemaker implantation which confirmed the physiopathological hypothesis of a catecholaminemediated stunning in tako-tsubo cardiomyopathy.
\end{abstract}

Keywords: Tako-Tsubo Syndrome; Isoprenaline; Pacemaker; Left Ventricular Dysfunction; Ventricular Dysfunction

\section{INTRODUCTION}

Tako-tsubo cardiomyopathy (TCM) typically occurs af- ter an intrinsic adrenergic hyperstimulation triggered by emotional or physical stress. Exceptionally, it may be due to an exogenous catecholergic input.

\section{CASE PRESENTATION}

We report the case of an 85 year old man who was hypertensive, with a previous history of ischemic stroke. He consulted for signs of heart failure with a recurrent dizziness after a two week period. The electrocardiogram (ECG) showed a heart rate of $40 \mathrm{bpm}$ with atrial fibrillation and a high degree atrioventricular block. The initial laboratory tests showed normal levels of troponin and echocardiography showed a left ventricular (LV) ejection fraction (LVEF) to $60 \%$ without any wall motion abnormalities. The patient was administered isoprenaline at a dose of $0.02 \mathrm{mcg} / \mathrm{kg} / \mathrm{min}$ for 20 hours before the implantation of a single chamber pacemaker. At 24 hours of admission an acute pulmonary edema with a rapid onset occurred. The ECG showed negative $\mathrm{T}$-waves in precordial leads (Figure 1). The control echocardiography showed impaired LVEF of $25 \%$ with akinesis and ballooning of the apex. The troponin I level rose to $2 \mathrm{ng} / \mathrm{ml}$ (normal $<0.04 \mathrm{ng} / \mathrm{ml}$ ) as well as creatinine kinase level (780 IU/l). The angiography carried out in emergency confirmed the tako-tsubo like aspect of the LV (Figure 2) but there were no significant lesions on the coronary angiogram. The acute pulmonary edema was treated by an intravenous infusion of furosemide and oxygen therapy. Subsequent evolution under beta-blocker and angiotensin converting enzyme inhibitor therapies was favorable with a regression of wall motion abnormalities and normalization of LVEF after 15 days.

\section{DISCUSSION}

Tako-tsubo cardiomyopathy (TCM) is characterized by an acute and reversible left ventricular dysfunction which, in its typical form, primarily affects the apex and often 


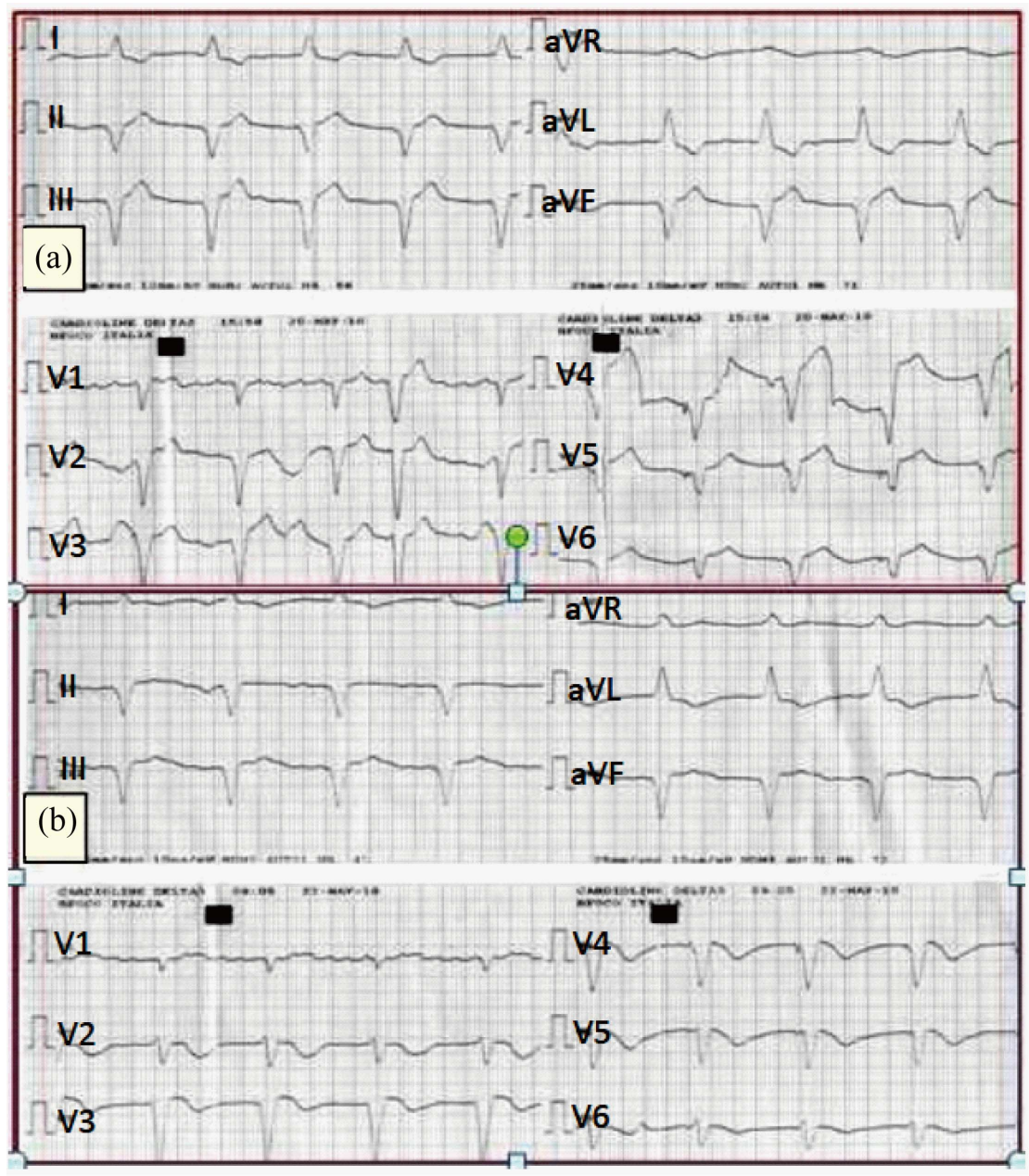

Figure 1. (a) Electrocardiogram immediately after pacemaker implantation; (b) Electrocardiogram 42 hours later; negative $\mathrm{T}$ waves in precordial leads.

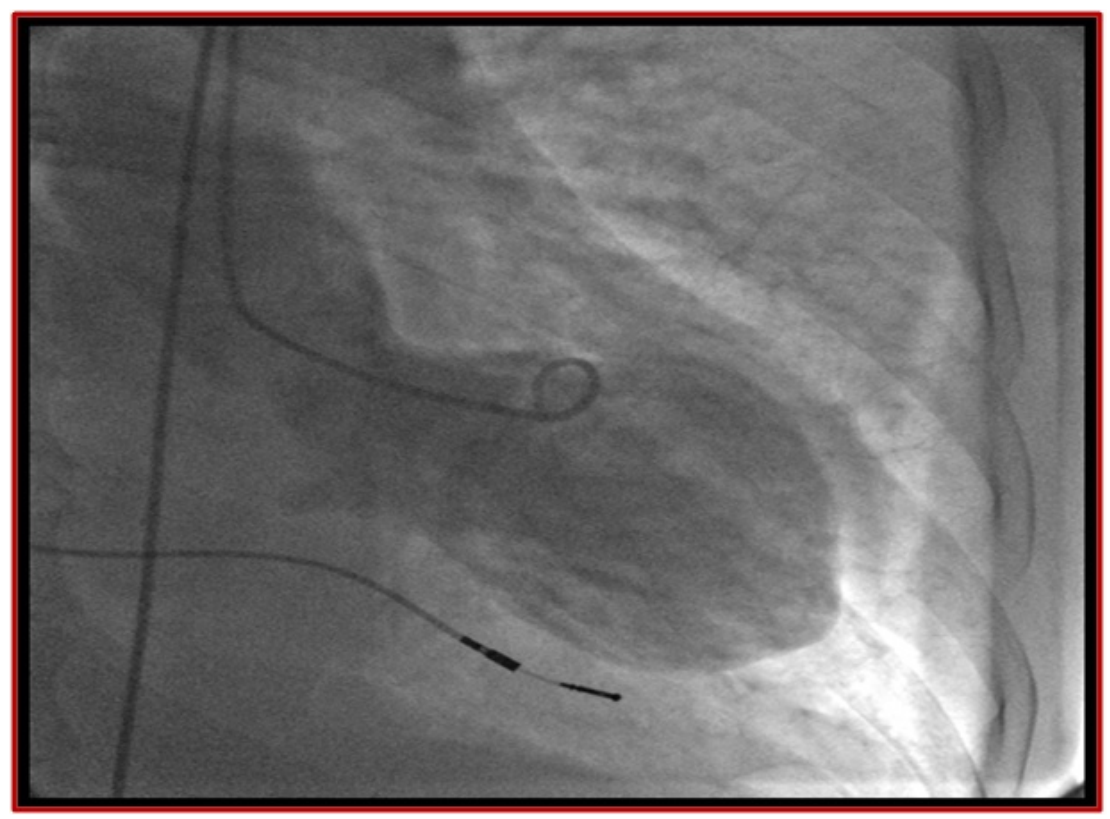

Figure 2. Left ventricular angiogram at systole; apical blooning. 
the median parts of the LV [1]. It is usually triggered by physical or emotional stress. The subsequent surge in catecholamine levels seems to be the main cause of TCM. Catecholamines bind $\beta 2$-adrenoceptors which activate, via the cyclicAMP, the inhibitory protein $\mathrm{G}$ pathway instead of the physiological stimulatory G protein (stimulus trafficking phenomenon). This results not only in a negative myocardial intropic effect but also in anti-apoptotic and myocardial regenerating effects through the PI3K-AKT signal accounting for the reversibility of this syndrome [2]. Several cases of TCM complicating exogenous catecholamines have been reported. Most of these cases in fact arose after inappropriate administration of epinephrine for anaphylactic shock [3]. These authors have also described cases of TCM following a dobutamine infusion indicated for inotropic support [4] or as part of a stress echocardiography (at peak [5] or the recovery phases [6]). To the best of our knowledge, there have been no reported cases of TCM described in the literature after the administration of isoproterenol which is a potent $\beta 1$ and $\beta 2$ adrenoceptor agonist. This was administered in our patient at the recommended doses. In an animal model, Mori et al. [7] showed myocardial fibrosis predominating to the apex after infusion of isoproterenol and concluded to a greater $\beta$ catecholergic sensitivity of the apex when compared to the base of the LV. Fewer than ten cases of TCM following the implantation of a pacemaker have been reported [8-11]. Unlike our case, these reports have involved only female patients who were treated with dual chamber pacemaker for atrioventricular conduction disorders. These patients were aged from 77 to 89 years. The patient described by Kimura et al. [12] was aged 54 years and had an associated sarcoidosis. The TCM occurred between 10 minutes and 3 days after the device implantation. The clinical presentation was variable between asymptomatic forms, chest pain, dyspnea, hypotension and acute pulmonary edema as in our patient. The common electrocardiographic sign was negative $\mathrm{T}$-waves in precordial leads. Normalization of ventricular function was obtained in 2 weeks - 9 weeks, but in two cases as described by Kurisu et al. [8] LV dysfunction persisted after 2 months - 4 months of follow-up. As in our case, Burnetti et al. [13] reported a case of TCM after both pacemaker implantation and catecholergic exogenous input in a 65 year old female patient who received orciprenaline. It is interesting to note that the conduction disorder itself can be the cause of TCM [14]. Also, we cannot dismiss the fact that the disease, the hospitalization in the intensive care unit or the intervention are as many conditions that could provoke the onset of a TCM [15].

\section{CONCLUSION}

This rare case of TCM that occurred in a male patient was probably multifactorial, and it raises further physiopathological questions that need to be elucidated.

\section{ACKNOWLEDGEMENTS}

The authors are grateful to Richard Medeiros, Rouen University Hospital Medical Editor, for editing the manuscript.

\section{REFERENCES}

[1] Gianni, M., Dentali, F., Grandi, A.M., et al. (2006) Apical ballooning syndrome or takotsubo cardiomyopathy: A systematic review. European Heart Journal, 27, 15231529. doi:10.1093/eurheartj/ehl032

[2] Nef, H.M., Möllmann, H., Akashi, Y.J., et al. (2010) Mechanisms of stress (Takotsubo) cardiomyopathy. Nature Reviews Cardiology, 7, 187-193. doi:10.1038/nrcardio.2010.16

[3] Dewachter, P. and Mouton-Faivre, C. (2010) Possible link between apical ballooning syndrome during anaphylaxis and inappropriate administration of epinephrine. $\mathrm{Ma}$ yo Clinical Proceeding, 85, 396-400. doi:10.4065/mcp.2009.0699

[4] Saito, R., Takahashi, T., Noshita, N., et al. (2010) Takotsubo cardiomyopathy induced by dobutamine infusion during hypertensive therapy for symptomatic vasospasm after subarachnoid hemorrhage-case report. Neurologia Medico-Chirurgica (Tokyo), 50, 393-395. doi:10.2176/nmc.50.393

[5] Margey, R., Diamond, P., McCann, H., et al. (2009) Dobutamine stress echo-induced apical ballooning (Takotsubo) syndrome. European Journal of Echocardiography, 10, 395-399. doi:10.1093/ejechocard/jen292

[6] Shah, B.N., Simpson, I.A. and Rakhit, D.J. (2011) Takotsubo (apical ballooning) syndrome in the recovery period following dobutamine stress echocardiography: A first report. European Journal of Echocardiography, 12, E5. doi:10.1093/ejechocard/jeq107

[7] Mori, H., Ishikawa, S., Kojima, S., et al. (1993) Increased responsiveness of left ventricular apical myocardium to adrenergic stimuli. Cardiovascular Research, 27, 192-198. doi:10.1093/cvr/27.2.192

[8] Kurisu, S., Inoue, I., Kawagoe, T., et al. (2006) Persistent left ventricular dysfunction in takotsubo cardiomyopathy after pacemaker implantation. Circulation Journal, 70, 641614. doi:10.1253/circj.70.641

[9] Chun, S.G., Kwok, V., Pang, D., et al. (2007) Transient left ventricular apical ballooning syndrome (takotsubo cardiomyopathy) as a complication of permanent pacemaker implantation. International Journal of Cardiology, 117, e27-e30. doi:10.1016/j.ijcard.2006.11.125

[10] Kohnen, R.F. and Baur, L.H.B. (2009) A Dutch case of a takotsubo cardiomyopathy after pacemaker Implantation. Netherlands Heart Journal, 17, 487-490. doi:10.1007/BF03086309

[11] Abu Sham'a, R.A., Asher, E., Luria, D., et al. (2009) Apical ballooning syndrome: A complication of dual chamber pacemaker implantation. Indian Pacing and Electro- 
physiology Journal, 9, 229-232.

[12] Kimura, K., Tanabe-Hayashi, Y., Noma, S., et al. (2007) Images in cardiovascular medicine. Rapid formation of left ventricular giant thrombus with Takotsubo cardiomyopathy. Circulation, 115, e620-e621. doi:10.1161/CIRCULATIONAHA.106.673947

[13] Brunetti, N.D., Ieva, R., Correale, M., et al. (2011) Combined exogenous and endogenous catecholamine release associated with tako-tsubo like syndrome in a patient with atrio-ventricular block undergoing pace-maker implantation. Acute Card Care, 13, 112-114.

$$
\text { doi:10.3109/17482941.2011.553236 }
$$

[14] Wielusiński, M., Kaźmierczak, J., Kiedrowicz, R., et al. (2011) Tako-tsubo cardiomyopathy following complete atrioven-tricular nodal heart block during transcatheter radiofrequency ablation of atrioventricular nodal reentrant tachycardia. Kardiologia Polska, 69, 508-509.

[15] Liu, S. and Dhamee, M.S. (2010) Perioperative transient left ventricular apical ballooning syndrome: Takotsubo cardiomyopathy: A review. Clinical Anesth, 22, 64-70. doi:10.1016/j.jclinane.2009.03.010 